\title{
TRANSFORMASI RUKUN HAJI KEDALAM PERANCANGAN PRODUK PLAYGROUND INDOOR SEBAGAI PENUNJANG PEMBELAJARAN AGAMA ISLAM PADA SEKOLAH TK DI SURABAYA
}

\author{
Sigit Firdaus Prayogi ${ }^{1}$, \\ Rizky Nur Fatayah ${ }^{2}$ \\ Institut Sains dan Teknologi Terpadu Surabaya ${ }^{l}$ \\ sigit@stts.edu
}

\begin{abstract}
Abstrak
Pendidikan adalah usaha sadar dan terencana untuk mengembangkan potensi di dalam diri untuk memiliki kekuatan spiritual keagamaan, kepribadian dan kecerdasan. Pengetahuan agama islam harus diberikan pada anak sejak usia dini. Setiap daerah di Indonesia memiliki berbagai lembaga pendidikan TK diantaranya TK yang berbasis islam. Fasilitas penunjang aktivitas didalam sekolah sudah seharusnya didapat oleh anak-anak TK islam. Seperti permainan playground dan fasilitas pembelajaran tentang ibadah haji. Namun sayangnya sarana permainan playground seperti yang terdapat pada sekolah TK islam di Surabaya belum menerapkan unsur islam didalamnya. Oleh sebab itu, tahap selanjutnya yaitu melakukan metode pengambilan data dengan cara wawancara dan pengambilan data dari berbagai sumber di internet. Data tersebut digunakan untuk melakukan studi dan analisa elemen yang dibutuhkan dalam perancangan, seperti aktivitas ibadah haji, konsep desain, ergonomi, sistem, material, dan warna. Setelah dilakukan studi dan analisa tersebut, dihasilkan sebuah final desain yang berupa indoor playground playfull yang mengambil inspirasi dari kegiatan ibadah haji dengan menggunakan sistem modular.
\end{abstract}

Kata kunci: Playground Indoor, Haji, Modular.

\begin{abstract}
Education is a conscious and planned effort to develop inner potential to have religious spiritual strength, personality and intelligence. Knowledge of Islamic religion must be given to children from an early age. Every region in Indonesia has various kindergarten educational institutions including Islamic-based kindergartens. Supporting facilities for activities within the school should be obtained by Islamic kindergarten children. Such as playground games and learning facilities about the haj pilgrimage. But unfortunately the playground facilities such as those found in Islamic Kindergartens in Surabaya have not implemented Islamic elements in them. Therefore, the next stage is to conduct data collection methods by means of interviews and data collection from various sources on the internet. The data is used to study and analyze the elements needed in the design, such as
\end{abstract}


the pilgrimage activities, design concepts, ergonomics, systems, materials, and colors. After the study and analysis were carried out, a final design was produced in the form of a playful indoor playground which took inspiration from the haj pilgrimage using a modular system.

Key words: Indoor Playground, Hajj, Modular.

\section{PENDAHULUAN}

Undang-Undang No. 20 Tahun 2003, pendidikan adalah usaha sadar dan terencana untuk mewujudkan suasana belajar dan proses pembelajaran agar peserta didik secara aktif mengembangkan potensi di dalam diri untuk memiliki kekuatan spiritual keagamaan, pengendalian diri, kepribadian, kecerdasan, akhlak mulia, serta keterampilan yang diperlukan dirinya, masyarakat, bangsa, dan negara. Jenjang pendidikan yang ditempuh oleh anak usia dini (PAUD) yaitu taman kanakkanak (TK). Tujuan dari pendidikan Taman Kanak-Kanak (TK) adalah untuk memberikan stimulasi dan bimbingan terhadap kebutuhan fisik dan pertumbuhannya, serta meningkatkan kemampuan intelektual dan hubungan sosial sebagai persiapan untuk masuk ke jenjang yang lebih tinggi.

Pendidikan yang diberikan kepada anak tidak hanya meliputi pengetahuan lokal namun juga diberikan pembekalan agama dan moral sejak dini. Sarana prasarana, dan fasilitas yang berkualitas merupakan standar yang harus dimiliki oleh setiap lembaga pendidikan untuk keberhasilan dan kelancaran suatu proses belajar mengajar dan memenuhi kebutuhan siswa TK. Tujuan dari adanya permainan playground tersebut yaitu untuk melatih motorik anak, selain itu juga dapat mengajarkan toleransi terhadap teman sebayanya karena pada saat itu anakanak bertemu bersama dan saling bersosialisasi. 

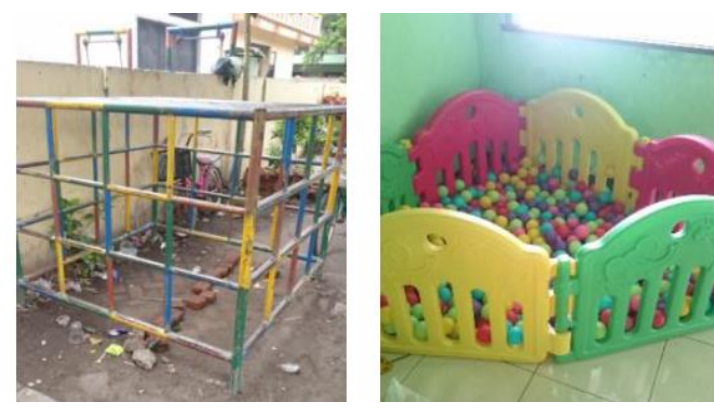

Gambar 1. Kondisi fisik playground

Sumber : Dokumentasi Pribadi

Gambar diatas merupakan kondisi fisik sarana yang terdapat disalah satu sekolah TK di Surabaya. Selain itu juga tidak memiliki ruang indoor yang cukup luas untuk bermain. Seharusnya fasilitas tersebut dapat berfungsi sebagaimana mestinya.

Oleh karena itu, akan dirancang sebuah playground indoor yang didalamnya mengandung unsur nilai-nilai Agama Islam yang tidak hanya melibatkan motorik halus, namun juga melibatkan motorik kasar pada anak.

\section{KAJIAN TEORI}

Pada bab ini akan menjelaskan beberapa teori pendukung yang digunakan dalam proses perancangan indoor playground islami.

\section{A. Playground}

Playground adalah area bermain atau taman bermain. Area bermain adalah tempat yang dirancang khusus untuk memungkinkan anak bermain di sana. Selain itu juga terdapat beberapa contoh konsep playground yang telah dilakukan oleh desainer luar negeri untuk memfasilitasi taman bermain anak. Seperti playground yang dirancang oleh Milos Todorovic berupa permainan ayunan yang dengan konsep curl. 


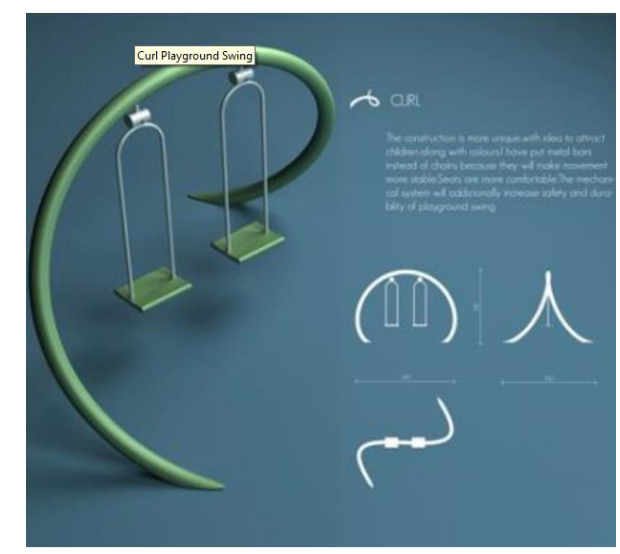

Gambar 2. Contoh konsep playground

Sumber : https://creativepool.com/milostodorovic/projects/curl

\section{B. Perkembangan Anak Usia Dini}

Pada tahap ini berisi data mengenai tahap-tahap perkembangan anak TK dari berbagai aspek. Menurut Harlimsyah (2007) perkembangan anak adalah segala perubahan yang terjadi pada diri anak dilihat dari berbagai aspek antara lain aspek fisik (motorik), emosi, kognitif dan psikososial.

\section{Pendidikan Agama Islam}

Pada pembahasan ini berisi mengenai pendidikan islam hingga data sekolah TK di Surabaya. Pendidikan islam di Indonesia sangat erat hubungannya dengan masuknya agama islam pertama kali di Indonesia. salah satu yang dilakukan yaitu melalui pendidikan. Dengan cara menghayati tujuan yang pada akhirnya dapat mengamalkan serta menjadikan Islam sebagai pandangan hidup. Seperti halnya belajar mengenai rukun islam yang ke-5 memiliki hikmah yang terkandung didalam pada setiap aktivitasnya. Sehingga pada setiap sekolah TK islam di Surabaya diberikan pelatihan manasik haji.

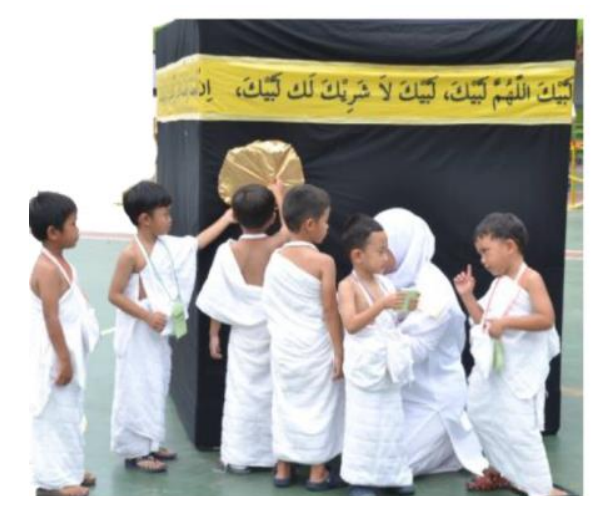

Gambar 3. Aktivitas Manasik Haji Anak 


\section{Ergonomi Anak Usia Dini}

Ergonomi memiliki keterkaitan dengan antropometri. Peran ergonomi sebagai ketentuan dalam keselamatan dan kenyamanan suatu aktivitas. Sedangkan antropometri sebagai sumber data tubuh manusia yang dibutuhkan dalam ergonomi. Ergonomi dan antropometri dibutuhkan dalam perancangan sebuah produk yang mendukung aktivitas manusia. Pada pembahasan ini terdapat data mengenai keselamatan untuk playground berupa standar dimensi pada permainan.

\section{E. Standar Material permainan Anak}

Material adalah sebuah masukan dalam produksi. Material seringkali adalah bahan mentah yang belum diproses, tetapi kadang kala telah diproses sebelum digunakan untuk proses produksi lebih lanjut. Material memiliki 2 jenis yaitu organik dan anorganik. Contoh material anorganik yaitu plastik. Material kayu sudah banyak digunakan dalam produk permainan anak-anak.

\section{F. Warna Kognitif Anak}

Ilmu tentang warna disebut chromatics. Para ahli warna J. Linschoten dan Drs. Mansyur juga menyebutkan dan menguraikan warna-warna itu bukan hanya suatu gejala yang dapat diamati saja, warna bisa mempengaruhi kelakuan dan kadang memegang peranan penting dalam penilaian estetis hingga turut menentukan suka tidaknya seorang manusia terhadap bermacam-macam benda. Terdapat 4 jenis warna yaitu primer, sekunder, tersier dan netral.

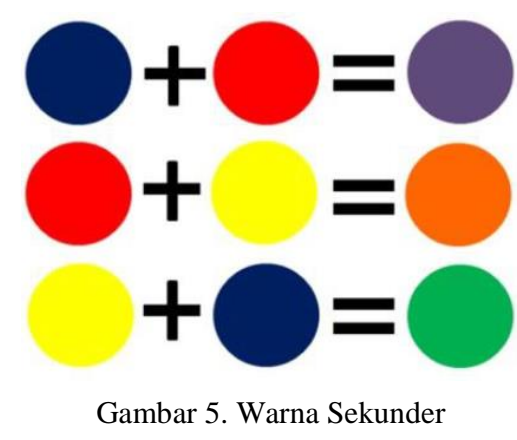

Selain itu pada tahap ini juga membahas mengenai psikologi dan kognitif warna pada anak TK. Data psikologi warna berupa klasifikasi warna. Sedangkan data kognitif tersebut berupa cara anak mengenal warna dengan menunjuk, menyebut dan mengelompokkan. 


\section{G. Sistem Modular Playground}

Sistem berasal dari bahasa Latin (systēma) dan bahasa Yunani (sustēma) adalah suatu kesatuan yang terdiri komponen atau elemen yang dihubungkan bersama untuk memudahkan aliran informasi, materi atau energi untuk mencapai suatu tujuan.

\section{METODE PENELITIAN}

Pada bab ini akan menjelaskan mengenai metode yang dilakukan untuk perancangan indoor playground islam.

\section{A. Langkah Awal}

Pada tahap awal dilakukan pengambilan data sekunder dari berbagai sumber buku dan internet. Selain itu juga dilakukan pengambilan data primer yang berupa observasi lapangan dan wawancara kepada stakeholder yang berhubungan dengan perancangan ini seperti guru dan pakar pemerhati anak disurabaya. Salah satu hasil wawancara yang telah dilakukan bahwa sekolah TK islam membutuhkan permainan yang menerapkan pembelajaran tentang ibadah haji. Permainan tersebut yang bersifat atraktif yang melibatkan motorik anak.

\section{B. Uraian Metodologi}

Setelah melakukan pengumpulan data dilanjutkan pada tahap inti dari proses perancangan ini. Tahap inti yang dilakukan berupa konsep desain dilakukan dengan cara membuat berbagai sketsa alternatif. Setelah melakukan pembuatan sketsa alternatif tersebut akan menemukan desain terpilih. Tahap selanjutnya yaitu pembuatan 3D modelling sesuai dengan sketsa terpilih. Sekaligus pembuatan gambar teknik. 


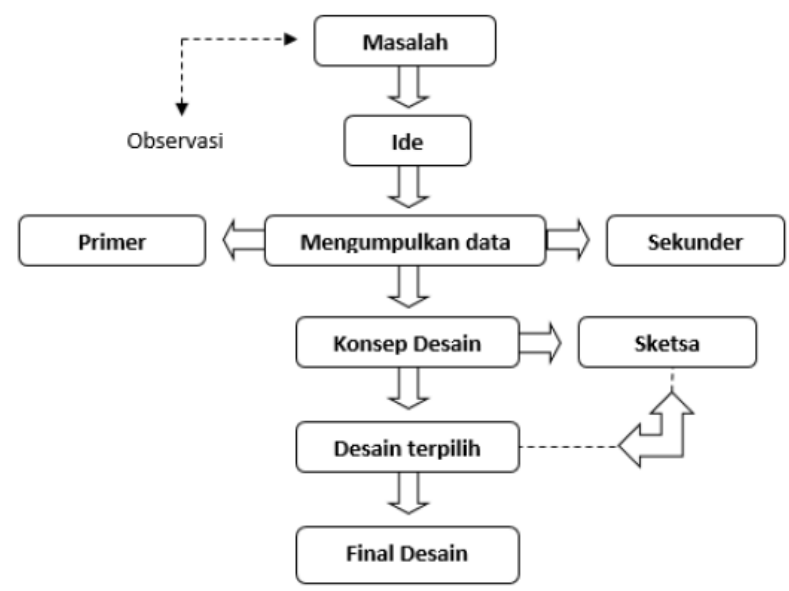

Gambar 6. Uraian Metodologi

\section{Langkah Akhir}

Setelah melakukan berbagai proses inti dari perancangan, dilakukan tahap akhir yang berupa pembuatan prototype produk dari sketsa terpilih.

\section{HASIL DAN PEMBAHASAN}

\section{A. Analisa Aktivitas Haji}

Pada tahap ini dilakukan analisa mengenai aktivitas dan kebutuhan dari ibadah haji. Terdiri dari 7 rute aktivitas inti yang dilakukan yakni ihram, tawaf, sai, wukuf, mabit, lempar jumroh dan tahallul.

Tabel 1. Analisa Kebutuhan

\begin{tabular}{|c|c|c|}
\hline No & Aktivitas Haji & \multicolumn{1}{c|}{ Kebutuhan } \\
\hline 1 & Ihram & $\begin{array}{l}\text { Berpakaian ihram, } \\
\text { Tertib, Gerakan }\end{array}$ \\
\hline
\end{tabular}

\begin{tabular}{|c|l|l|}
\hline 2 & Tawaf & Gerakan kaki, berhitung \\
\hline 3 & Sa'i & Gerakan kaki, berhitung \\
\hline 4 & Wukuf di Arafah & $\begin{array}{l}\text { Tenda, tim work, } \\
\text { gerakan kaki }\end{array}$ \\
\hline 5 & $\begin{array}{l}\text { Mabit di } \\
\text { Muzdalifah }\end{array}$ & Istirahat, Batu \\
\hline 6 & Melontar Jumrah & $\begin{array}{l}\text { Tugu jumrah, gerakan } \\
\text { kaki dan tangan, } \\
\text { navigasi }\end{array}$ \\
\hline 7 & Tahllul & Tertib, navigasi, gunting \\
\hline
\end{tabular}

Sumber: Pribadi 


\section{B. Studi dan Analisa Konsep Pembelajaran}

Pada tahap ini akan dilakukan analisa konsep pembelajaran yang akan diterapkan pada indoor playground. Konsep pembelajaran yang diterapkan berupa hikmah dari setiap rute aktivitas haji. Selain itu juga menerapkan permainan yang memiliki kesamaan aktivitas dengan rute ibadah haji. Seperti pada rute ihram menerapkan permainan tic toc toe. Permainan yang dipilih sebelumnya dilakukan perhitungan matriks.

Tabel 2. Mainan dan unsur Ihram

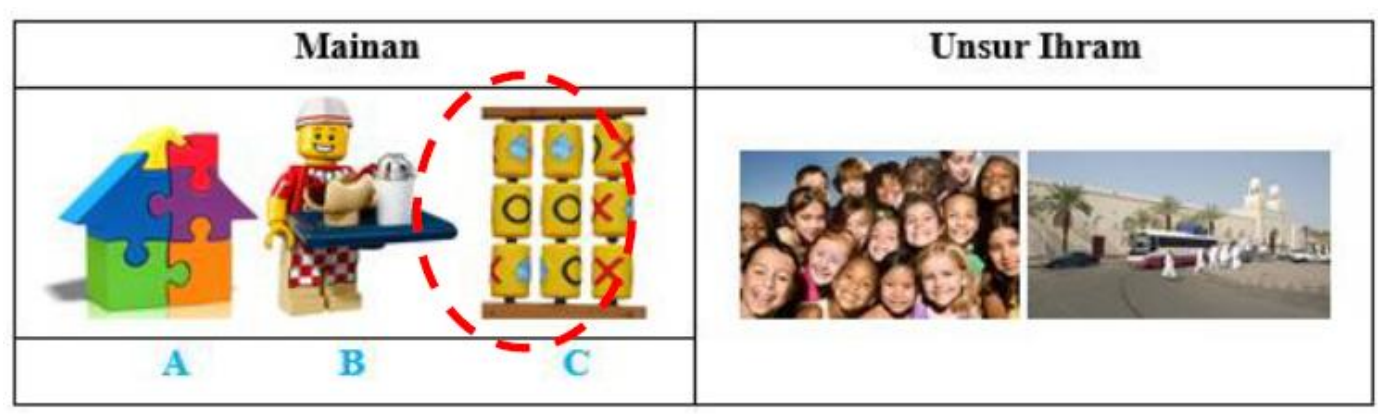

Sumber: Pribadi

\section{Analisa Desain}

Pada tahap ini akan membahas mengenai sketsa awal hingga desain terpilih. Dari desain terpilih tersebut akan dijelaskan mengenai konsep desain yang terdapat pada desain terpilih. Seperti pada rute pertama mengambil konsep desain dari bagian atas bangunan masjid bir ali.

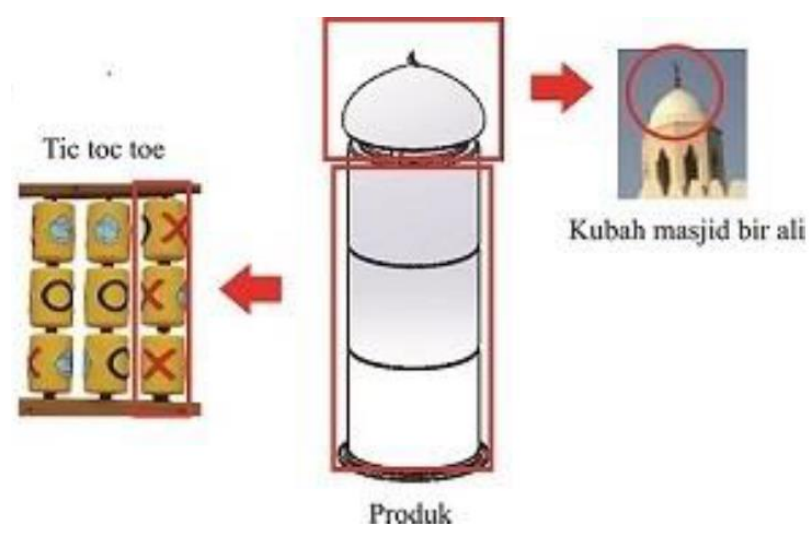

Gambar 8. Contoh Konsep Rute Ihram

Sumber : Hasil Analisa Peneliti 


\section{Analisa Ergonomi}

Pada tahap ini berisi ergonomi pada anak usia prasekolah. Meliputi antropometri anak dan peraturan yang berhubungan dengan keselamatan anak. Selain itu juga terdapat hasil pengukuran dimensi tubuh anak.

\section{E. Analisa Sistem Modular}

Penerapan sistem modular untuk mempermudah mobilitas playground tersebut ketika digunakan didalam dan diluar ruangan..

\section{F. Analisa Material}

Tahap analisa material memiliki 2 jenis kategori material yaitu material utama dan material penunjang. Material utama yang digunakan yaitu plywood dan besi sebagai rangka. Sedangkan material penunjang seperti busa, kasa dan fabric.

\section{G. Analisa Warna}

Pada tahap analisa warna ini, terdapat hasil penelitian warna favorit pada anak TK. Hasil dari penelitian yang telah dilakukan yaitu mayoritas menyukai warna yang tergolong warna sekunder.

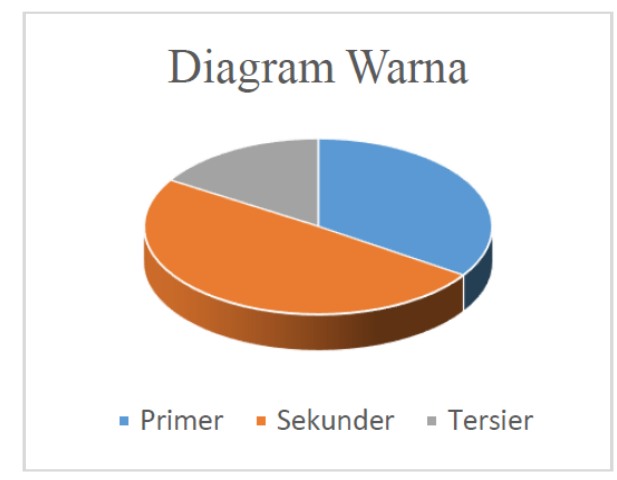

Gambar 9. Hasil Penelitian Warna

Sumber : Hasil Survey terhadap anak TK Studi Kasus Surabaya 


\section{FINAL DESAIN}

Pada bab ini menjelaskan segala macam tentang final desain dari produk indoor playground islami yang penulis rancang, yaitu hasil final desain pada setiap part dalam bentuk 3D hingga akan ditampilkan. Fitur produk dan proses pembuatan akan ditampilkan pula.

\section{A. Final Desain indoor playground islam}

Pada tahap ini berisi mengenai tampilan produk playground secara keseluruhan dan per item produk inti. Selain itu juga terdapat gartek dari setiap produk yang telah dibuat.

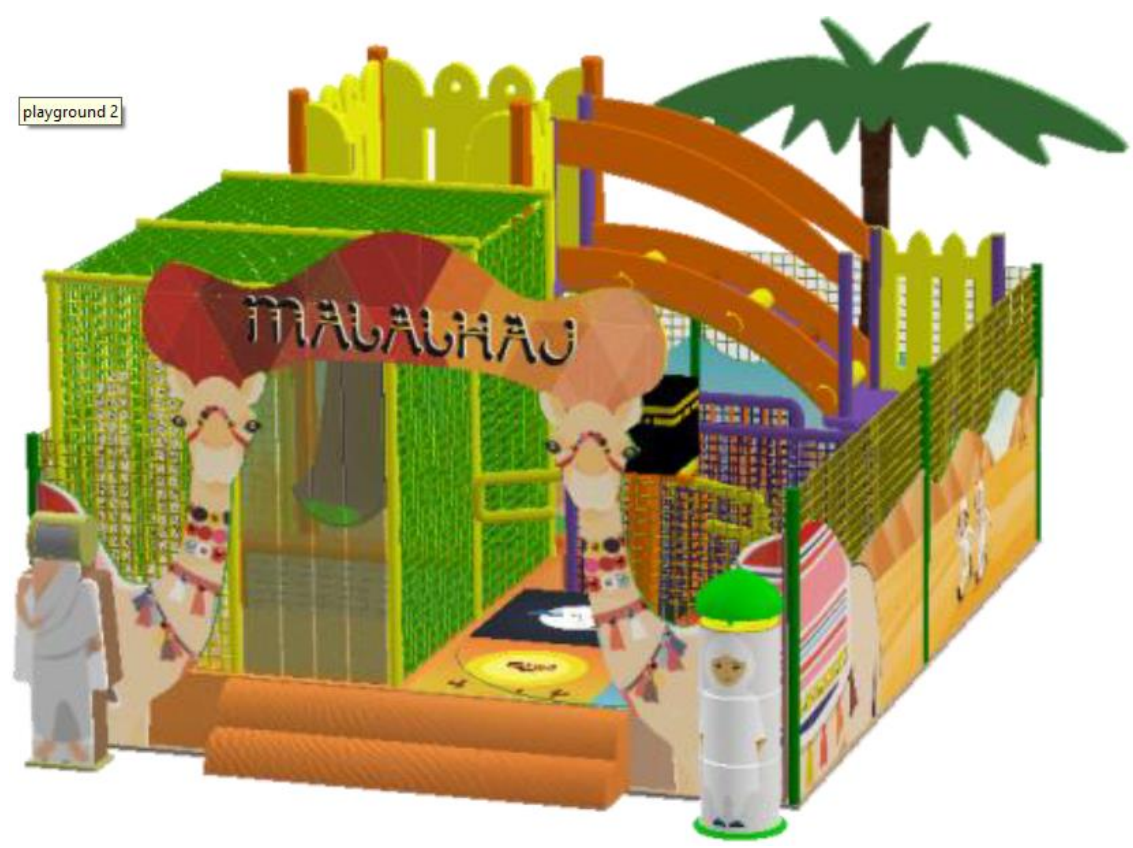

Gambar 10. Final Desain

Sumber : Hasil Rendering Pribadi

\section{B. Fitur Desain}

Pada produk yang telah dirancang terdapat fitur-fitur desain yang diterapkan. Fitur tersebut yang meliputi cara pengaplikasian produk. 


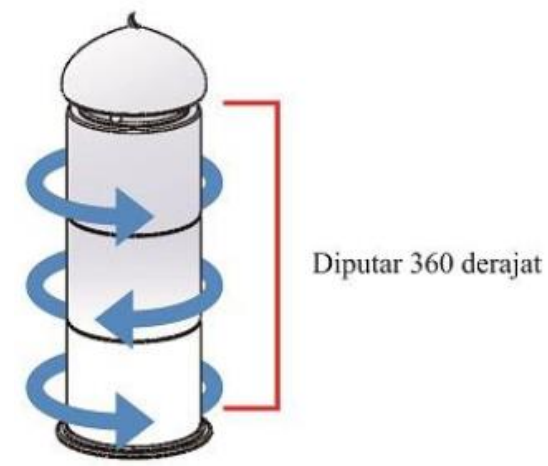

Gambar 11. Fitur Desain

Sumber : Hasil Rendering Pribadi

\section{Proses Produksi}

Setelah dilakukan proses final desain dalam bentuk digital 3D modelling, akan dibuat proses pembuatan protorype sesuai dengan analisa yang telah dilakukan. Menggunakan material PVC dalam pembuatan prototype.

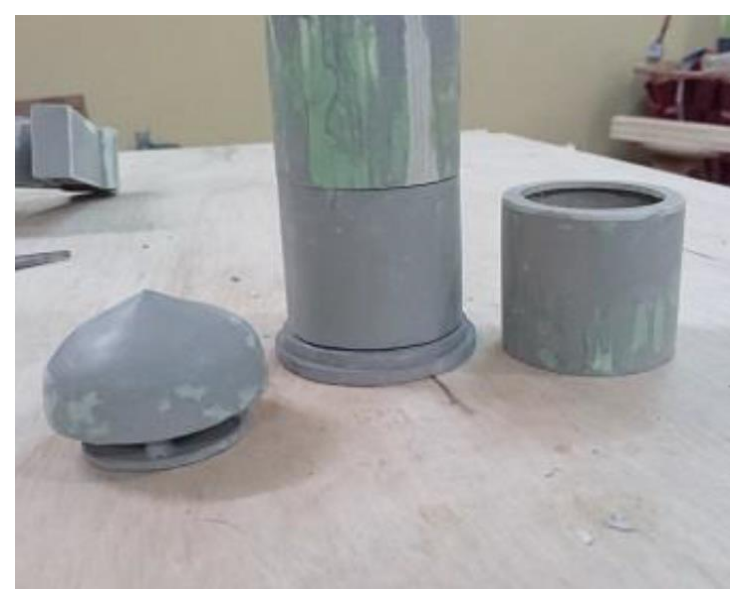

Gambar 12. Contoh Proses Produksi

Sumber : Dokumentasi Peneliti

\section{SIMPULAN DAN SARAN}

\section{Simpulan}

Merancang indoor playground dengan konsep islami yang menerapkan konsep aktivitas ibadah haji dapat memberikan pelatihan manasik haji dengan cara bermain. Selain itu secara tidak langsung anak mempelajari hikmah dari setiap rute pada aktivitas ibdah haji tersebut. Sistem modular yang digunakan memudahkan ketiak playground tersebut dirakit dan efisiensi biaya produksinya. 


\section{Saran}

Dalam pengembangan desain permainan anak dengan mengambil nilai dari spiritual dan Agama Islam harus dilakukan evaluasi kepada anak TK untuk diketahui respon dan tanggapan sebagai data untuk perbaikan desainnya.

\section{DAFTAR PUSTAKA}

Albrect dan Miller, 2000. The Comprehensif Infant Curriculum. Beltsville MD: Gryphon House Ins.

Darunnajah, 2012. Standart kompetensi anak. Diakses tanggal 20 oktober 2018 dari http://darunnajah.com/standarkompetensi-anak-tk/

Haji dan umroh, 2017. Hikmah ibadah haji dan umroh. Diakses tanggal 15 mei 2018 dari https://media.ihram.asia/2017/02/14/mabit dan-tahallul-apahikmahnya-hikmah-ibadah-haji-umrah-3/

Psyline, 2017. Arti dan Pengaruh Warna bagi Psikologi Manusia, Diakses tanggal 20 oktober 2018 dari https://psyline.id/arti-dan-pengaruh-warna-bagipsikologi-manusia

Salabi, Ahmad, 1954. History of Muslim Education. Bairut: Dar Al-Kasyaf.

Shofia, Naila, 2004. Manajemen Pelatihan Manasik Haji pada anak-anak. Studi Kasus Pada RA Khurriyatul Fikri Pasuruhan Lor Jati Kudus (Skripsi Sarjana). Universitas Negeri Islam Walisongo Semarang. 